\title{
SINGLETON PRETERM BIRTHS IN KORLE BU TEACHING HOSPITAL, ACCRA, GHANA - ORIGINS AND OUTCOMES
}

\author{
${ }^{*}$ K. NKYEKYER, CHRISTABEL ENWERONU-LARYEA ${ }^{1}$ AND T. BOAFOR ${ }^{2}$ \\ Departments of Obstetrics \& Gynaecology and ${ }^{1}$ Child Health, University of Ghana Medical School, \\ Accra, Ghana and ${ }^{2}$ Department of Obstetrics \& Gynaecology, \\ Korle Bu Teaching Hospital, Accra, Ghana
}

\begin{abstract}
SUMMARY
Objective: To determine the singleton preterm birth rate, the relative proportions of the clinical categories of preterm births and to compare the outcomes in these categories.

Setting: Department of Obstetrics \& Gynaecology, Korle Bu Teaching Hospital.

Participants: Preterm births from $1^{\text {st }}$ July to $31^{\text {st }}$ December 2003.

Results: Out of a total of 4731 singleton births 440 were preterm, giving a preterm birth rate of $9.3 \%$. One hundred and eighty-five $(42 \%$, [95\% Confidence Interval (CI) 37.4\%, 46.8\%]) preterm births followed spontaneous onset of preterm labour (group A), 82 (18.6\%, [95\% CI 15.2\%, 22.7\%]) followed preterm premature rupture of membranes, PPROM (group B) and 173 (39.3\%, [95\% CI $34.8 \%, 44.1 \%])$ were medically indicated (group C). The commonest indication for delivery in group $\mathrm{C}$ was severe pre-eclampsia/eclampsia. Although there was no significant difference in the mean gestational ages at delivery between the groups, babies in group $\mathrm{C}$ had significantly lower birth weights. No differences in sex ratios, stillbirth rates, or incidence of low Apgar scores were found. Babies in group $\mathrm{C}$ were significantly more likely to be admitted to the neonatal intensive care unit (NICU) and had a significantly higher perinatal death rate. Survivors of NICU admission among group $\mathrm{C}$ babies spent significantly longer periods in hospital before discharge.

Conclusion: Outcomes of preterm births in Korle $\mathrm{Bu}$ Teaching Hospital are less favourable among indicated preterm births than among spontaneous or PPROM-related preterm births. A detailed study of the causes of neonatal morbidity and mortality is suggested to determine any differences between the three groups.
\end{abstract}

Keywords: Singleton preterm births, clinical categories, outcomes.

\section{INTRODUCTION}

Preterm birth, defined as birth before 37 completed weeks of gestation, is the major clinical problem associated with perinatal mortality, serious neonatal morbidity and moderate to severe childhood disability in developed countries ${ }^{1}$. In the Korle Bu Teaching Hospital prematurity is the cause of almost $54 \%$ of early neonatal deaths ${ }^{2}$. Singleton preterm birth rates vary from one part of the world to another: studies have reported rates of $5.5 \%$ in New South Wales (Australia) $)^{3}, 9.7 \%$ in the USA ${ }^{4}$, $3 \%$ in Jordan ${ }^{5}, 5.4 \%$ in Scotland ${ }^{6}, 15.2 \%$ in Zimbabwe $^{7}$ and $20.3 \%$ in rural Malawi ${ }^{8}$.

Preterm births have been categorized on the basis of type of clinical presentation into: preterm births following spontaneous preterm labour, those resulting from preterm delivery following preterm premature rupture of membranes (PPROM), and medically indicated preterm births ${ }^{9}$. The propriety of this classification of preterm births has been questioned on the basis that it does not necessarily reflect important differences in the underlying etiologic processes. It is argued that differences in clinical presentation may be more a reflection of differences in availability and accessibility of care than of etiological differences ${ }^{10}$. Medical and obstetric conditions necessitating preterm delivery have been reported in more than a quarter of women with PPROM and those with spontaneous preterm births, suggesting that coexisting medical conditions may influence the occurrence of either PPROM or preterm labour ${ }^{11}$. However, in a study which examined the relationship of maternal risk factors to the type of singleton preterm delivery, the evidence suggested that distinguishing between types of spontaneous preterm births may not lead to useful etiological inferences whereas the distinction between spontaneous preterm deliveries and those that are medically indicated seems valid $^{12}$.

\footnotetext{
* Author for correspondence
} 
As regards outcomes, studies have indicated differences in neonatal outcomes for the various categories of preterm births. The risks of neonatal mortality and morbidity as well as long term pulmonary consequences appear to be greater in infants born preterm by indicated delivery than in preterms born spontaneously at corresponding weeks $^{13}$. The prevalence of small for gestational age infants is higher in the medically indicated preterm birth group than in the other two ${ }^{14,15}$. The effectiveness of antenatal steroids seems to depend on the clinical subtype of preterm birth, with the greatest effect observed in the adequate for gestational age infant delivered after preterm labour with intact membranes and the least effect in cases of pregnancy associated with maternal hypertension or fetal growth restriction ${ }^{16}$.

The aims of this study, conducted at the Korle $\mathrm{Bu}$ Teaching Hospital, were to determine the singleton preterm birth rate, the relative proportions of the various clinical categories and to compare the outcomes in these categories.

\section{PATIENTS AND METHODS}

Between $1^{\text {st }}$ July and $31^{\text {st }}$ December 2003 the notes of women carrying singleton pregnancies who delivered preterm were examined within twentyfour hours of delivery and the appropriate data collected. Preterm birth was defined as delivery before 37 completed weeks of gestation and women were included if the date of the last menstrual period was reliably known and/or there was ultrasound confirmation of gestational age. Where gestational age could not be determined by any of these means but delivery was obviously preterm the neonatal estimation of gestational age (expanded Ballard score) ${ }^{(17)}$ by the paediatrician, on admission of the baby to the neonatal intensive care unit (NICU), was used. Women who delivered macerated stillbirths were excluded.

Maternal demographic data collected included age and parity. Concerning the antenatal period the occurrence of antepartum complications (hypertension, antepartum haemorrhage) was noted. For each case it was determined which clinical type of preterm birth it fell into: spontaneous preterm birth (group A), preterm birth following PPROM (group $\mathrm{B}$ ), or medically indicated preterm birth (group C). For group $\mathrm{C}$ the indication for the preterm birth was also noted. The gestational age at delivery, mode of delivery, and the sex, birth weight and Apgar scores of the baby were recorded. If there was admission to NICU the indication, duration and outcome of admission were noted from the NICU records.

The data was analyzed using Epi-info 2000. Categorical variables were compared using $\chi^{2}$ tests while numerical variables were compared using one-way analysis of variance (ANOVA). Differences were considered significant if $\mathrm{p}<0.05$.

\section{RESULTS}

During the period of study there were four hundred and forty singleton preterm births. The total number of singleton births was 4731, thus giving a singleton preterm birth rate of $9.3 \%$. One hundred and eighty-five $(42 \%$, [95\% Confidence Interval (CI) $37.4 \%, 46.8 \%$ ]) of the preterm births followed spontaneous onset of preterm labour (group A), 82 (18.6\%, [95\% CI 15.2\%, 22.7\%]) followed preterm premature rupture of membranes (group B) and $173(39.3 \%$, [95\% CI 34.8\%, 44.1\%]) were medically indicated (group C). The mean maternal age for the whole group was 27.9(SD6.2) years and the mean parity 1.2(SD1.4).

The indications for delivery in group $\mathrm{C}$ were as follows: severe pre-eclampsia -102 patients $(59 \%)$, eclampsia - 32(18.5\%), abruptio placentae $23(13.3 \%)$, placenta praevia - 7(4.0\%), severe IUGR - 6(3.5\%), severe oligohydramnios $2(1.2 \%)$ and one patient with a history of two previous intrauterine fetal deaths at term who was delivered electively at 36 weeks gestation.

In group A, $42(22.7 \%)$ women had hypertension and $17(9.2 \%)$ had antepartum haemorrhage; the figures for group B were 7 (8.5\%) and 2 (2.4\%) respectively.

One hundred and ninety-three (43.9\%) of the women were delivered by Caesarean section. Twenty-one $(10.9 \%)$ of this number were in group A, $15(7.8 \%)$ were in group B and $153(81.3 \%)$ were in group $\mathrm{C}$. The Caesarean delivery rate in group C (88.4\%) was significantly much higher than that in group A $(11.4 \%)$ or B $(18.3 \%)$ $(\mathrm{p}<0.00001)$.

\section{Gestational age at delivery and birth weight}

The mean gestational age at delivery was 32.6(SD2.9) weeks for the whole group. The mean gestational age at delivery was not significantly different between the three groups (Table 1). However, the mean birth weight was significantly lower in group $\mathrm{C}$ than it was in either group $\mathrm{A}$ or $B$; there was no significant difference in the mean birth weights in groups A and B (Table 2). 
The lowest gestational age was 24 weeks. The smallest baby weighed 500gms and the heaviest 3300 gms.
Babies' condition at birth and outcomes (Table 3)

There was no significant difference in sex ratios between babies in the various clinical groups.

Table 1 Gestational age at delivery in the various clinical categories

\begin{tabular}{|c|c|c|c|c|}
\hline \multirow{2}{*}{$\begin{array}{c}\text { Gestational age (completed } \\
\text { weeks) at delivery }\end{array}$} & \multicolumn{3}{|c|}{ Number in group (\% of group total) } & \multirow{2}{*}{$\begin{array}{r}\text { Total (\% of } \\
\text { whole group) }\end{array}$} \\
\hline & A (\%) & $\mathbf{B}(\%)$ & C (\%) & \\
\hline$<28$ & $9(4.9)$ & $2(2.4)$ & $8(4.6)$ & 19(4.3) \\
\hline $28-29$ & $22(11.9)$ & $12(14.6)$ & $31(17.9)$ & $65(14.8)$ \\
\hline $30-31$ & $22(11.9)$ & $11(13.4)$ & $22(12.7)$ & $55(12.5)$ \\
\hline $32-33$ & $40(21.6)$ & $16(19.5)$ & $28(16.2)$ & 84(19.1) \\
\hline $34-35$ & $54(29.2)$ & $26(31.7)$ & $59(34.1)$ & 139(31.6) \\
\hline 36 & $38(20.5)$ & $15(18.3)$ & $25(14.5)$ & 78(17.7) \\
\hline Total & 185(100) & 82(100) & 173(100) & $440(100)$ \\
\hline Mean(SD) & $32.7(3.0)$ & $32.7(2.9)^{9}$ & $32.4(2.9)^{\pi}$ & $32.6(2.9)$ \\
\hline
\end{tabular}

Table 2 Birth weight in the various clinical categories

\begin{tabular}{|c|c|c|c|c|}
\hline \multirow{2}{*}{$\begin{array}{l}\text { Birthweight } \\
\text { (gms) }\end{array}$} & \multicolumn{3}{|c|}{ Number in group (\% of group total) } & \multirow{2}{*}{$\begin{array}{c}\text { Total (\% of } \\
\text { whole group) }\end{array}$} \\
\hline & A & B & C & \\
\hline$<1000$ & $13(7.0 \%)$ & $3(3.7 \%)$ & $19(11 \%)$ & $35(8.0 \%)$ \\
\hline $1000-1499$ & $28(15.1 \%)$ & $13(15.9 \%)$ & $42(24.3 \%)$ & 83(18.9\%) \\
\hline $1500-2499$ & $115(62.2 \%)$ & $52(63.4 \%)$ & $90(52.0 \%)$ & $257(58.4 \%)$ \\
\hline$\geq 2500$ & $29(15.7 \%)$ & $14(17.1 \%)$ & $22(12.7 \%)$ & $65(14.8 \%)$ \\
\hline Total & $185(100 \%)$ & $82(100 \%)$ & $173(100 \%)$ & $440(100 \%)$ \\
\hline Mean(SD) & $1869.9(556.4)^{* *}$ & $1925.0(548.7)^{* *}$ & 1723.8(575.5)** & \\
\hline
\end{tabular}

Table 3 Babies' condition at birth and outcomes

\begin{tabular}{|c|c|c|c|c|}
\hline \multirow[t]{2}{*}{ Parameter } & \multicolumn{3}{|c|}{ Number in group (\% of relevant group total) } & \multirow[t]{2}{*}{ P value } \\
\hline & A & B & $\mathrm{C}$ & \\
\hline Sex: Female & $96(51.9 \%)$ & $39(47.6 \%)$ & $93(53.8 \%)$ & 0.65 \\
\hline Male & $89(48.1 \%)$ & $43(52.4 \%)$ & $80(46.2 \%)$ & $\left(\chi^{2}=0.86\right)$ \\
\hline Livebirths & $163(88.1 \%)$ & $77(93.9 \%)$ & $147(85.0 \%)$ & 0.122 \\
\hline Stillbirths & $22(11.9 \%)$ & $5(6.1 \%)$ & $26(15.0 \%)$ & $\left(\chi^{2}=4.20\right)$ \\
\hline \multicolumn{5}{|c|}{ Apgar scores of livebirths } \\
\hline 1-minute: $<7$ & $91(55.8 \%)$ & $42(54.5 \%)$ & $96(65.3 \%)$ & 0.16 \\
\hline$\geq 7$ & $72(44.2 \%)$ & $35(45.5 \%)$ & $51(34.7 \%)$ & $\left(\chi^{2}=3.73\right)$ \\
\hline 5-minute: $<7$ & $37(22.7 \%)$ & $19(24.7 \%)$ & $45(30.6 \%)$ & 0.27 \\
\hline$\geq 7$ & $126(77.3 \%)$ & $58(75.3 \%)$ & $102(69.4 \%)$ & $\left(\chi^{2}=2.61\right)$ \\
\hline \multicolumn{5}{|l|}{ NICU admission } \\
\hline Yes & $85(52.1 \%)$ & $40(51.9 \%)$ & $96(65.3 \%)$ & 0.031 \\
\hline No & $78(47.9 \%)$ & $37(48.1 \%)$ & $51(34.7 \%)$ & $\left(\chi^{2}=6.93\right)$ \\
\hline \multicolumn{5}{|c|}{ Outcomes of NICU admissions: } \\
\hline Discharged & $52(61.2 \%)$ & $29(72.5 \%)$ & $58(60.4 \%)$ & 0.38 \\
\hline Died & $33(38.8 \%)$ & $11(27.5 \%)$ & $38(39.6 \%)$ & $\left(\chi^{2}=1.94\right)$ \\
\hline \multicolumn{5}{|c|}{$\begin{array}{l}\text { Perinatal deaths (stillbirths } \\
\text { plus early neonatal deaths): }\end{array}$} \\
\hline Yes & $48(25.9 \%)$ & $11(13.4 \%)$ & $58(33.5 \%)$ & 0.003 \\
\hline No & $137(74.1 \%)$ & $71(86.6 \%)$ & $115(66.5 \%)$ & $\left(\chi^{2}=11.60\right)$ \\
\hline
\end{tabular}


Twenty-two (11.9\%) of babies in group A, $5(6.1 \%)$ in group B and $26(15.0 \%)$ in group $C$ were stillborn. There was no significant difference in the stillbirth rates in the three categories. Of the 387 live births, 229(59.2\%) had low one-minute Apgar scores $(<7)$; by the fifth minute 101(26.1\%) babies had low Apgar scores. There was no significant difference in the incidence of low Apgar scores at one and five minutes among the three groups.

A total of 221 babies (57.1\% of live births) were admitted to the neonatal intensive care unit (NICU). Babies in group $\mathrm{C}$ were significantly more likely to be admitted to the NICU. One hundred and thirty-nine babies survived the NICU admission to be discharged home, thus giving a NICU survival rate of $62.9 \%$. There was no significant difference in outcomes of NICU admissions (as far as deaths or discharges were concerned) among the groups.

One hundred and seventeen (52.9\%) of the 221 NICU admissions were simply on account of the babies being preterm; 48(21.7\%) had in addition asphyxia and 33(14.9\%) grunting respiration. For another $23(10.4 \%)$ there were such complications as small for gestational age, offensive liquor, weak cry, meconium aspiration and being infants of diabetic mothers.

Sixty-four (78\%) of the 82 deaths after NICU admission occurred within the first week of life; 26 were in group A, 6 in group B and 32 in group C. Thus there was a total of 117 perinatal deaths out of the 440 deliveries, giving a perinatal mortality rate of 265.9/1000 births for the whole group. Perinatal deaths were significantly more likely to occur among babies in group $\mathrm{C}$ than those in the other groups. The perinatal mortality rates were 259.5/1000, 134.1/1000 and 335.3/1000 births for groups $\mathrm{A}, \mathrm{B}$, and $\mathrm{C}$ respectively.

Eighty (97.6\%) of deaths in the NICU occurred within twenty-eight days of life; the remaining two babies died at thirty-one and thirty-two days of life respectively.

There was no significant difference, between the three groups, in the duration of survival among deaths after NICU admission (A-4.4(SD5.0), B9.7(SD11.4), C-4.6(SD7.6) days, $\mathrm{p}=0.098)$. However, among babies discharged after NICU admission, those in group $\mathrm{C}$ had significantly longer periods of hospitalisation than those in the two other groups (A-2.9(SD2.4), B-3.6(SD3.3), C7.7(SD3.4) days, $\mathrm{p}<0.0001)$.

\section{DISCUSSION}

The preterm birth rate of $9.3 \%$ in this study is identical to what was obtained for singleton births in a previous retrospective study at the Korle $\mathrm{Bu}$ Teaching Hospital which compared twin and singleton births ${ }^{18}$. It is also comparable to the $9.7 \%$ reported from the United States of America ${ }^{4}$. However, it is higher than the $3 \%$ to $5.9 \%$ in New South Wales (Australia), Jordan and Scotland ${ }^{3,5,6}$. Total preterm birth rates (singleton and multiple pregnancies) of $12.5 \%$ and $11.1 \%$ have been reported from Ile-Ife (Nigeria) and Lome (Togo) respectively ${ }^{19,20}$. It is likely that singleton preterm birth rates in these two places will be comparable to that in Korle $\mathrm{Bu}$ Teaching Hospital. The rate in Korle $\mathrm{Bu}$ is much lower than the $15.2 \%$ and $20.3 \%$ reported from Zimbabwe $^{7}$ and Malawi ${ }^{8}$ respectively. Some preterm births of unknown gestational age may have been missed in the present study because the babies may not have been admitted to the NICU; however, it is considered that the number is most likely to be too small to have affected the preterm birth rate to any great extent.

The proportion of indicated preterm births in this study, $39.3 \%$, is among the highest to be reported whilst the proportions from the other two groups fall within the ranges reported from other centres ${ }^{9}$. This shows the greater importance of indicated preterm births as a contributor to preterm deliveries in Korle Bu Teaching Hospital when compared to other centres. Severe hypertensive disease (severe pre-eclampsia and eclampsia) being the commonest reason for indicated preterm births is consistent with what has been reported elsewhere, though the proportion it forms in the indicated preterm birth group in this study, $77.5 \%$ (134 out of 175), is much higher ${ }^{13,21}$. It is important to note that although there is no significant difference in the mean gestational age at delivery in the three groups, babies in group $\mathrm{C}$ had a significantly lower mean birth weight than those in groups A and B. This may be attributable to intrauterine growth restriction which is more likely to occur in women with hypertensive disease in pregnancy ${ }^{22}$. In addition, though there is increased incidence of intrauterine growth restriction in preterm births the incidence and severity in indicated preterm births are much higher than those in spontaneous or premature rupture of membranes (PROM) related preterm births ${ }^{14,23}$. 
The very high Caesarean delivery rate in group $\mathrm{C}$ compared to the other groups concurs with what has been reported from New Mexico, $\mathrm{USA}^{21}$ and Finland $^{13}$. The situation at the Korle Bu Teaching Hospital is the result of the management practices concerning severe pre-eclampsia/eclampsia and abruptio placentae in the hospital. When the blood pressure has been controlled and steps have been taken to control or prevent fits (in severe preeclampsia/eclampsia), or when blood volume has been restored and coagulopathies corrected (in abruptio placentae) the next step is delivery of the baby. Unless the cervix is favourable enough for one to anticipate vaginal delivery within a few hours, Caesarean section is resorted to in order to minimise unfavourable maternal outcomes, even where the foetus is dead. Since in preterm pregnancies the cervix is unlikely to be favourable most of such women are delivered by Caesarean section.

There is no significant difference in the incidence of stillbirths or in the prevalence of low Apgar scores in the three clinical categories. The absence of any significant differences in low Apgar scores lends support to the findings in another study that antenatal maternal history and pregnancy complications (such as pre-eclampsia and vaginal bleeding) and events in labour like the use of oxytocin, magnesium and narcotics are not clearly associated with low Apgar scores ${ }^{24}$.

There is evidence in this study of greater neonatal morbidity among babies in the indicated preterm birth group than in the other two groups. They were more likely to be admitted to the NICU, and their survivors of NICU admission spent significantly longer periods in hospital before discharge. In addition, perinatal mortality was significantly higher in the indicated preterm birth group. These all suggest that outcomes of preterm births in Korle $\mathrm{Bu}$ Teaching Hospital are less favourable among indicated preterm births than among spontaneous or PPROM-related preterm births.

This study did not look in detail at the causes of morbidity and mortality in the neonates; it will be helpful to study these details so as to determine whether there are any differences among the three groups. However, the less favourable outcomes among babies in the indicated preterm births group may be related to their lower birthweights, most probably resulting from greater severity of intrauterine growth restriction; it is known that in preterm births of the same gestational age the outcomes worsen with decreasing birth weights ${ }^{5,15,25}$.
In conclusion, the singleton preterm birth rate in Korle Bu Teaching Hospital is 9.3\%. Preterm birth following spontaneous onset of labour is the commonest category, followed closely by medically indicated preterm births and then preterm births following preterm PROM. There is evidence of less favourable outcomes for indicated preterm births, which may be related to the significantly lower birthweights of babies in that group, although there is no significant difference in the mean gestational age at delivery among the three groups. A detailed study of the causes of neonatal morbidity and mortality is suggested in order to determine if there are any differences among the three groups.

\section{ACKNOWLEDGEMENT}

We would like to express sincerest gratitude to the nursing and midwifery staff of the Maternity Block and the NICU of the Korle $\mathrm{Bu}$ Teaching Hospital for their invaluable help in retrieving mothers' and babies' notes for examination during the study.

\section{REFERENCES}

1. Lumley J. Defining the problem: the epidemiology of preterm birth. BJOG: an International Journal of Obstetrics and Gynaecology, 2003; 110 (Suppl.20): 3-7.

2. Anyebuno M. Perinatal mortality in Korle $\mathrm{Bu}$ Teaching Hospital, Accra. Ghana Med J 1996; 30: 710-714.

3. Roberts CL, Algert CS, Raynes-Greenow C, Peat B, Henderson-Smart DJ. Delivery of singleton preterm infants in New South Wales, 1990-1997. Austral N Zeal J Obstet Gynaecol 2003; 43: 32-37.

4. Reagan PB, Salsberry PJ. Race and ethnic differences in determinants of preterm birth in the USA: broadening the social context. Soc Sc Med. 2005; 60: 2217-2228.

5. Ziadeh SM. Obstetrical outcomes amongst preterm singleton births. Saudi Med J 2001; 22: $342-346$.

6. Magowan BA, Bain M, Juszczak E, McInneny K. Neonatal mortality amongst Scottish preterm singleton births (1985-1994). Br J Obstet Gynaecol 1998; 105: 1005-1010. 
7. Feresu S.A, Harlow S.D, Welch K, Gillespie B.W. Incidence of and socio-demographic risk factors for stillbirth, preterm birth and low birthweight among Zimbabwean women. Paediatr Perinat Epid 2004; 18: 154-163

8. Nynke van den Broek, Chikonde Ntonya, Edith Kayira, Sarah White, James P. Neilson. Preterm birth in rural Malawi: high incidence in ultrasound-dated population. Hum Reprod 2005; 20: 3235-3237.

9. Moutquin J-M. Classification and heterogeneity of preterm births. BJOG: an International Journal of Obstetrics and Gynaecology 2003; 110(Supplement 20): 30-33

10. Klebanoff M.A, Shiono P.H. Top down, bottom up and inside out: reflections on preterm birth. Paediatr Perinat Epid 1995;9:125-129.

11. Matthieu V, Moutquin J-M. Analyse des facteurs de risques associés aux categories d'accouchements prematurés à Sherbrook, Québec, Canada. CHUS 11 août 2000.

12. Pickett K.E, Abrams B, Selvin S. Defining preterm delivery - the epidemiology of clinical presentation. Paediatr Perinat Epid 2000; 14: 305-308.

13. Kurkinen-Raty $M$, Koivisto $M$, Jouppila P. Preterm delivery for maternal or fetal indications: maternal morbidity, neonatal outcome and late sequelae in infants. BJOG: an International Journal of Obstetrics and Gynaecology 2000; 107: 648-655.

14. Zeitlin J, Ancel PY, Saurel-Cubizolles MJ, Papiernik E. The relationship between intrauterine growth restriction and preterm delivery: an empirical approach using data from a European case-control study. BJOG: an International Journal of Obstetrics and Gynaecology 2000; 107: 750-758.

15. Villar J, Abalos E, Carroli G, Giordano D, Wojdyla D, Piaggio G, et al. W.H.O. Antenatal Care Trial Research Group. Heterogeneity of perinatal outcomes in the preterm delivery syndrome. Obstet Gynecol 2004; 104: 78-87.
16. Elimian A, Verma U, Canterino J, Shah J, Visintainer P, Tejani N. Effectiveness of antenatal steroids in obstetric subgroups. Obstetrics and Gynecology 1999; 93: 174-179.

17. Ballard J.L, Khoury J.C, Wedig K, Wang L, Eilers-Walsman B.L, Lipp R. New Ballard Score, expanded to include extremely premature infants. J Pediatr 1991; 119: 417-423.

18. Nkyekyer K. Twin and singleton births in Ghana - a case-control study. Twin Res 2002; 5: $265-269$

19. Kuti O, Owa J.A. Gestational age-specific neonatal mortality among preterm singleton births in a Nigerian tertiary institution. Int $J$ Gynecol Obstet 2003; 80: 319-320

20. Balaka B, Baeta S, Agbere A.D, Boko K, Kessie K, Assimadi K. Risk factors associated with prematurity at the University Hospital of Lome, Togo. Bull Soc Pathol Exot 2002; 95: 280-283

21. Fronterhouse W, Christensen F.C, Rayburn L.A, Gilson G.J, Curet L.B, Rayburn W.F. Mandated preterm delivery: its prevalence and impact at a tertiary referral center. $J$ Matern Fetal Med 2001; 10: 162-165.

22. Yitzhak M, Bar J, Mazor M, Fraser D, Leiberman JR, Hod M, Kaplan B. Increased rate of small-for-gestational-age neonates in pre-eclamptic women with preterm deliveries. J Obstet Gynaecol 1999; 19: 135-138.

23. Hediger M.L, Scholl T.O, Schall J.I, Miller W.M, Fischer R.L. Fetal growth and the etiology of preterm delivery. Obstet Gynecol 1995; 85: $175-182$

24. Weinberger B, Anwar M, Hegyi T, Hiatt M, Koons A, Paneth N. Antecedents and neonatal consequences of low Apgar scores in preterm newborns. Arch Pediatr Adolesc Med 2000; 154: 294-300.

25. Garite T.J, Clark R, Thorp J.A. Intrauterine growth restriction increases morbidity and mortality among premature neonates. Am $J$ Obstet Gynecol 2004; 191: 481-487. 